\title{
SELEÇÃO DE LOTES DE SEMENTES DE Pinus taeda L. PARA A CULTURA DE TECIDOS
}

\author{
Diego Pascoal Golle ${ }^{1 *}$, Lia Rejane Silveira Reiniger², Marlove Fátima Brião Muniz², Joana Hanauer², Andressa \\ Vasconcelos Flôres ${ }^{3}$, Enrique Astério Benitez León ${ }^{4}$
}

\begin{abstract}
*Autor para correspondência: dgolle@unicruz.edu.br
RESUMO: Neste trabalho, objetivou-se identificar os principais gêneros fúngicos associados a três lotes de sementes de Pinus taeda L.; avaliar a qualidade sanitária e fisiológica desses lotes, para utilizar como critério de seleção para a cultura de tecidos e analisar o estabelecimento in vitro de explantes de origem seminal. Foi possível discriminar os lotes quanto à qualidade sanitária e fisiológica, bem como estabelecer in vitro plantas de Pinus taeda, a partir de nós cotiledonares obtidos da germinação asséptica de sementes de um lote selecionado pela qualidade sanitária e fisiológica. Os meios nutritivos MS, $1 / 2$ MS e WPM são igualmente adequados para esse fim. Para a análise sanitária, os gêneros fúngicos Fusarium, Penicillium e Trichoderma são os de maior sensibilidade. Para a avaliação fisiológica mostraram-se adequadas as variáveis: plântulas anormais, plântulas normais fortes, comprimento, massa fresca e massa seca de plântulas normais fortes. As análises mostraram-se favoráveis à escolha de lotes de sementes para o cultivo in vitro e todos os meios de cultura utilizados foram adequados ao estabelecimento da espécie em cultura de tecidos.
\end{abstract}

Palavras-chave: vigor de sementes, sanidade de sementes, estabelecimento in vitro, sementes florestais.

\section{SELECTION OF SEED LOTS OF Pinus taeda L. FOR TISSUE CULTURE}

\begin{abstract}
The aim of this work was to identify the fungi genera associated with three Pinus taeda L. seed lots and to assess the sanitary and physiological quality of these lots for use as selection criteria for tissue culture and evaluate the in vitro establishment of explants from seminal origin in different nutritive media. It was possible to discriminate the lots on the sanitary and physiological quality, as well as to establish in vitro plants of Pinus taeda from cotyledonary nodes obtained from aseptic seed germination of a selected lot by the sanitary and physiological quality higher. The nutritive media MS, $1 / 2$ MS and WPM were equally suitable for this purpose. For the sanitary analysis the fungal genera Fusarium, Penicillium and Trichoderma were those of the highest sensitivity. For the physiological evaluation were important the variables: abnormal seedlings, strong normal seedlings; length, fresh and dry weight of strong normal seedlings. The analyzes were favorable to choose lots of seeds for in vitro culture and all culture media were adequate for the establishment of this species in tissue culture.
\end{abstract}

Keywords: seed vigor, seed sanity, in vitro establishment, forestry seeds

\section{INTRODUÇÃO}

Pinus taeda L. (PINACEAE) é uma das espécies florestais mais cultivadas para fins de florestamento e reflorestamento, além de apresentar excelente qualidade madeireira (MARCHIORI, 1996). A escolha dessa espécie também está ligada às características industriais que apresenta e ao potencial ornamental (LORENZI et al., 2003), além de possuir rápido crescimento, o que a permite atingir grandes incrementos anuais em altura (SELLE et al., 1994). Plantios florestais de alta produtividade são indispensáveis para o desenvolvimento de sistemas silviculturais rentáveis. No setor florestal, a técnica de cultura de tecidos denominada micropropagação é a mais difundida, apresentando aplicações comprovadas (XAVIER et al., 2009). Antes de se efetuar a micropropagação propriamente dita, os explantes devem ser estabelecidos in vitro, isto é, após a inoculação no meio nutritivo e exposição ao ambiente controlado, devem responder formando novos primórdios foliares ou radiculares.

Utilizar sementes como fonte de explantes para o estabelecimento in vitro apresenta duas vantagens significativas: inicialmente, a juvenilidade dos explantes que pode otimizar as respostas in vitro, e depois a variabilidade genética presente em um lote de sementes de espécies alógamas ou com sistemas mistos de cruzamento, permitindo a ampliação da probabilidade de sucesso da metodologia pela avaliação para uma ampla gama de genótipos.

1 Universidade de Cruz Alta - Cruz Alta, Rio Grande do Sul, Brasil

2 Universidade Federal de Santa Maria - Santa Maria, Rio Grande do Sul, Brasil

3 Universidade Federal de Santa Catarina - Curitibanos, Santa Catarina, Brasil

4 Universidade Nacional de Assunção - San Lorenzo, Paraguai

Cerne, Lavras, v. 20, n. 2, p. 259-266, abr./jun. 2014 
As características sanitárias e fisiológicas constituem-se em um bom critério para a escolha de lotes, cujas sementes apresentem boa qualidade (DEBERGH; READ, 1991), porém, não há, até o presente, registro de trabalhos realizados com esse fim. Sementes com boa qualidade sanitária apresentam reduzida incidência ou até mesmo ausência de microrganismos associados, facilitando os procedimentos de desinfestação superficial necessários para a obtenção de cultivos assépticos. Da mesma maneira, lotes com elevada germinação e vigor proporcionam o adequado estabelecimento in vitro de um número suficiente de culturas, que possibilitam a realização das fases subsequentes da micropropagação: multiplicação, alongamento, enraizamento e aclimatização.

Os meios nutritivos utilizados na cultura de tecidos e fornecem as substâncias essenciais ao crescimento dos tecidos e controlam, em grande parte, o padrão de desenvolvimento in vitro. Baseiam-se nas exigências das plantas quanto aos nutrientes minerais, com algumas modificações para atender às necessidades específicas nas condições de cultivo in vitro (CALDAS et al., 1998; TORRES et al., 2001). De maneira geral, o meio nutritivo Woody Plant Medium - WPM, desenvolvido por Lloyd e Mccown (1981) é costumeiramente utilizado em cultura de tecidos de espécies lenhosas, pois possui concentrações de sais minerais balanceadas para essas plantas, porém, o meio MS (MURASHIGE; SKOOG, 1962) e suas diluições, também, têm apresentado resultados positivos no cultivo in vitro (MANTOVANI; FRANCO, 1998).

Conduziu-se este trabalho com os objetivos de identificar os principais gêneros fúngicos associados aos lotes de sementes de Pinus taeda L., avaliar a qualidade sanitária e fisiológica dos lotes para utilizar como critério de seleção para emprego na cultura de tecidos e analisar o estabelecimento in vitro, em diferentes meios nutritivos, de explantes obtidos a partir da germinação asséptica de sementes do lote selecionado.

\section{MATERIAIS E MÉTODOS}

Neste trabalho, foram utilizados três lotes de sementes de Pinus taeda, os quais são oriundos de área de produção de sementes e foram denominados como: lote A de $1^{\text {a }}$ geração (LA1), lote B de $1^{\text {a }}$ geração (LB1) e lote B de $2^{\mathrm{a}}$ geração (LB2). LA1 corresponde a lote de sementes procedente de Ponta Alta do Norte (SC), oriundas de um povoamento originado a partir de sementes que vieram da África do Sul, mas com origem na planície costeira leste dos Estados Unidos da Améria (EUA). O lote LB1 é composto por sementes procedentes de povoamentos de Otacílio da Costa (SC), as quais tiveram origem na Carolina do Sul (EUA). O lote LB2 é procedente de Angatuba (SP), também originou-se de povoamento formado por sementes vindas da Carolina do Sul (EUA).

Análise da qualidade sanitária e fisiológica: foram realizados dois experimentos conduzidos em delineamento inteiramente casualizado, com oito repetições por tratamento, sendo cada repetição composta por 25 sementes. Os diferentes lotes foram considerados tratamentos. A metodologia descrita nas Regras para Análise de Sementes (BRASIL, 2009) foi utilizada como base para os testes. Em câmara de fluxo laminar, as sementes foram dispostas em caixas plásticas tipo Gerbox, contendo três folhas de papel filtro previamente esterilizadas e umedecidas com água estéril até atingir a proporção de três vezes a massa do papel. Todos os materiais utilizados (exceto as sementes) foram desinfestados com etanol a $70 \%(\mathrm{v} / \mathrm{v})$ e hipoclorito de sódio $(\mathrm{NaOCl})$ comercial a 2,5\% $(\mathrm{v} / \mathrm{v})$, permanecendo expostos durante 30 minutos à luz ultravioleta. Após a introdução das sementes, as caixas foram envolvidas em sacos plásticos para conservar da umidade e mantidas em sala de crescimento com temperatura de $25^{\circ} \mathrm{C} \pm 3$ e fotoperíodo de 16 horas, com intensidade luminosa de 20 $\mu \mathrm{mol} \mathrm{m} \mathrm{m}^{-2} \mathrm{~s}^{-1}$ fornecida por lâmpadas fluorescentes tipo luz do dia.

$\mathrm{Na}$ análise da sanidade, aos sete dias, foi realizada a identificação dos gêneros fúngicos por meio de observações das sementes com o auxílio de microscópio estereoscópico e microscópio óptico. Lâminas provisórias foram confeccionadas retirando-se, com o auxílio de agulhas histológicas, uma amostra do micélio fúngico, contendo estruturas de reprodução, confeccionando-se lâminas provisórias coradas à base de azul de metileno a $0,3 \%(v / v)$. Os gêneros fúngicos identificados foram quantificados em porcentagem.

$\mathrm{Na}$ avaliação da qualidade fisiológica das sementes, aos sete dias, efetuou-se a primeira contagem de germinação, sendo considerada como semente germinada toda aquela em que houve protrusão do tegumento pela radícula e, aos 28 dias, foram quantificadas, percentualmente, as variáveis: sementes mortas (que apresentaram deterioração ou secreção purulenta), sementes duras (não germinadas, com aspecto enrijecido), plântulas anormais (que não se enquadram em um padrão de desenvolvimento normal, apresentando má formação de parte aérea ou radícula), plântulas normais fracas (plântulas que se desenvolvem

Cerne, Lavras, v. 20, n. 2, p. 259-266, abr./jun. 2014 
normalmente, mas com pouco crescimento em relação às demais) e plântulas normais fortes (plântulas de desenvolvimento normal, com aspecto vigoroso, bom desenvolvimento da radícula e da parte aérea, possuindo tamanho expressivo); massa fresca (g), a massa seca (g) e o comprimento $(\mathrm{cm})$ das plântulas classificadas como normais fortes. Para a determinação da massa seca, as plântulas foram acondicionadas em sacos de papel e mantidas em estufa a $50^{\circ} \mathrm{C}$ até atingirem massa constante.

Estabelecimento in vitro de Pinus taeda L.: sementes do lote LA1, selecionadas a partir dos resultados observados nos ensaios descritos anteriormente, foram embebidas em água destilada por 48 horas e, após, foram inoculadas em frascos contendo algodão hidrófilo embebido em água estéril, permanecendo em sala de cultivo com temperatura de $25^{\circ} \mathrm{C} 3$ e fotoperíodo de 16 horas com intensidade luminosat de $20 \mu \mathrm{mol} \mathrm{m}^{-2} \mathrm{~s}^{-1}$, fornecidos por lâmpadas fluorescentes tipo luz do dia.

Aos 14 dias, as plântulas que já estavam emitindo os cotilédones foram coletadas e mantidas em copo de Becker contendo água estéril. A desinfestação das plântulas consistiu em: imersão em etanol a 70\% (v/v) durante 30 segundos; lavagem em água estéril e imersão sob agitação em solução de hipoclorito de sódio $(\mathrm{NaOCl})$ a 3\% (v/v) durante 5 minutos; enxágue triplo em água destilada estéril. Foram excisados nós cotiledonares com $1 \mathrm{~cm}$ de comprimento, os quais foram inoculados nos frascos contendo meio nutritivo previamente autoclavado durante 20 minutos à temperatura de $121^{\circ} \mathrm{C}$ e $1 \mathrm{~atm}$ de pressão. As unidades experimentais foram mantidas em sala de cultivo, onde permaneceram nas mesmas condições descritas anteriormente para a germinação das sementes. Testaram-se três diferentes meios nutritivos: MS, $1 / 2 \mathrm{MS}$, que é obtido por meio da diluição do MS à metade de sua concentração normal de sais e WPM. O experimento foi conduzido em delineamento inteiramente casualizado com sete repetições, sendo cada uma composta por três frascos com capacidade para $150 \mathrm{~mL}$ contendo $30 \mathrm{~mL}$ de meio nutritivo e um explante. Aos 40 dias, avaliaramse: estabelecimento (\%), de formação de brotos (\%) e o comprimento dos brotos $(\mathrm{cm})$.

Análises estatísticas: em todos os experimentos a normalidade dos dados avaliada por meio do teste de Kolmogorov-Smirnov e a homogeneidade de variâncias pelo teste de Bartlett. Quando necessário, os dados foram transformados pela função e submetidos à análise de variância. Quando o valor de "F" foi significativo, as médias foram comparadas por meio do teste de Tukey ao nível de $5 \%$ de probabilidade de erro. As análises estatísticas foram realizadas com o software Estat, desenvolvido pelo
Departamento de Estatística da Universidade Estadual Paulista - UNESP (1994).

\section{RESULTADOS E DISCUSSÃO}

Análise da qualidade sanitária: verificou-se a incidência de nove gêneros fúngicos nos lotes: Aspergillus, Cercospora, Cladosporium, Curvularia, Fusarium, Penicillium, Pestalotia, Rhizoctonia e Trichoderma. Foi possível discriminar os lotes, sendo para esta finalidade os gêneros Fusarium, Penicillium e Trichoderma os mais experessivos (Tabela 1).

Tabela 1 - Porcentagem de incidência de gêneros fúngicos nos lotes de sementes de Pinus taeda L. Santa Maria-RS, UFSM, 2007.

Table 1 - Percentage of incidence of fungal genus in the seed lots of Pinus taeda L. Santa Maria-RS, UFSM, 2007.

\begin{tabular}{lccccc}
\hline \multirow{2}{*}{ Gênero } & \multicolumn{5}{c}{ Lote de Sementes } \\
\cline { 2 - 6 } & LA1 $^{*}$ & LB1 & LB2 & Média & CV (\%) \\
\hline Aspergillus & $0,0 \mathrm{a}^{* *}$ & $0,5 \mathrm{a}$ & $1,0 \mathrm{a}$ & 0,5 & 1,31 \\
Cercospora & $0,5 \mathrm{a}$ & $1,0 \mathrm{a}$ & $0,0 \mathrm{a}$ & 0,5 & 1,31 \\
Cladosporium & $0,5 \mathrm{a}$ & $0,0 \mathrm{a}$ & $0,5 \mathrm{a}$ & 0,3 & 1,13 \\
Curvularia & $0,0 \mathrm{a}$ & $0,5 \mathrm{a}$ & $0,0 \mathrm{a}$ & 0,1 & 0,8 \\
Fusarium & $0,5 \mathrm{a}$ & $17,5 \mathrm{~b}$ & $0,0 \mathrm{a}$ & 6,0 & 6,2 \\
Penicillium & $12,5 \mathrm{~b}$ & $14,5 \mathrm{~b}$ & $1,0 \mathrm{a}$ & 9,3 & 5,9 \\
Pestalotia & $1,5 \mathrm{a}$ & $3,5 \mathrm{a}$ & $0,5 \mathrm{a}$ & 1,8 & 4,03 \\
Rhizoctonia & $0,0 \mathrm{a}$ & $1,0 \mathrm{a}$ & $0,0 \mathrm{a}$ & 0,3 & 1,05 \\
Trichoderma & $3,5 \mathrm{a}$ & $11,0 \mathrm{a}$ & $36,0 \mathrm{~b}$ & 16,8 & 7,96 \\
\hline
\end{tabular}

${ }^{*}$ lote A de $1^{\text {a }}$ geração (LA1), lote B de $1^{\text {a }}$ geração (LB1) e lote B de $2^{\text {a }}$ geração (LB2). ${ }^{* *}$ Médias seguidas pela mesma letra, na linha, não diferem estatisticamente pelo teste de Tukey ao nível de $5 \%$ de probabilidade de erro. A letra "a" é atribuída ao resultado considerado mais satisfatório na avaliação de qualidade das sementes.

A contaminação por Aspergillus não diferiu estatisticamente entre os três lotes analisados. Esse microrganismo é conhecido por sua ocorrência em sementes armazenadas, com destaque entre os fungos mais frequentes em lotes de sementes de Pinus (SANTOS et al., 2001). Outras espécies florestais também apresentam ocorrência de Aspergillus, como relatado para Pterogyne nitens Tul. (NASCIMENTO et al., 2006).

Cerne, Lavras, v. 20, n. 2, p. 259-266, abr./jun. 2014 
A incidência do gênero Cercospora também não diferiu entre os lotes. Cercospora, agente causal da cercosporiose (GRIGOLETTI JUNIOR; AUER, 1996), já foi relatado em sementes de Acacia mearnsii De Wild., onde, igualmente, não apresentou incidência diferenciada nos lotes testados (SANTOS et al., 2001). Não houve diferenças estatísticas entre os lotes de $P$. taeda para os gêneros Curvularia, Rhizoctonia, e Pestalotia. Curvularia e Rhizoctonia que incluem-se nos gêneros fúngicos responsáveis pelo damping-off, uma conhecida patologia florestal, responsável pelo tombamento de mudas (CARNEIRO, 1987). Pestalotia também está relacionado a uma doença das espécies florestais denominada needle cast, comum em pináceas. Esse gênero também é atribuído ao anelamento da haste e às manchas necróticas em viveiros de Eucalyptus (ALFENAS et al., 2004).

A incidência do gênero Fusarium revelou diferenças significativas entre os lotes, com LA1 e LB2 não diferindo entre si e apresentando reduzidas médias de contaminação por esse patógeno, de $0,5 \%$ e $0 \%$ respectivamente. Este patógeno foi também registrado em sementes de Casearia sylvestris (BITTENCOURT; HOMECHIN, 1998) e de Acacia mearnsii De Wild. (SANTOS et al., 2001). O gênero Fusarium costuma infectar várias regiões das plantas. Seus esporos podem sobreviver nas sementes e serem introduzidos em novas áreas (PIZZINATO, 1991).

O gênero Penicillium apresentou menor contaminação em LB2 (1\%), que apresentou maior qualidade sanitária no tocante a esse gênero em relação aos lotes LA1 (12,5\%) e LB1 (14,5\%) que, por sua vez, não diferiram. Penicillium é um típico fungo de armazenamento, relatado em vários gêneros florestais como Pinus, Peltophorum, Acacia, Eucalyptus e Cedrella (SANTOS et al., 2001).

O gênero Trichoderma, a exemplo de Fusarium e Penicillium, permitiu a discriminação dos lotes, com LA1 e LB1 apresentando 3,5\% e 11\% de contaminação por esse gênero, e não diferindo entre si; enquanto LB2 foi apresentou o maior índice de contaminação (36\%). Muito frequente em sementes de espécies florestais, o gênero Trichoderma é utilizado no controle biológico de outros fungos (BETTIOL; GHINI, 1995).

Análise da qualidade fisiológica: os percentuais de germinação aos sete dias não foram eficientes na estratificação dos lotes, resultado que se assemelha aos observados por Alves et al. (2005) em Mimosa caesalpinnifolia Benth. Da mesma maneira, não se observaram diferenças entre os lotes avaliados aos 28
Tabela 2 - Análise do vigor de três lotes de sementes de Pinus taeda L. através do desempenho de plântulas. Santa Maria, UFSM, 2007.

Table 2 - Analysis of vigor of three seed lots of Pinus taeda L. through performance of seedlings. Santa Maria, UFSM, 2007.

\begin{tabular}{cccc}
\hline Lote & $\mathrm{G}^{*}(\%)$ & $\mathrm{SM}(\%)$ & $\mathrm{SD}(\%)$ \\
\hline LA1 & $5,0 \mathrm{a}^{* *}$ & $1,5 \mathrm{a}$ & $21,25 \mathrm{a}$ \\
LB1 & $12,0 \mathrm{a}$ & $4,5 \mathrm{a}$ & $29,50 \mathrm{a}$ \\
LB2 & $4,5 \mathrm{a}$ & $6,5 \mathrm{a}$ & $27,0 \mathrm{a}$ \\
Média & 7,16 & 4,16 & 25,91 \\
CV (\%) & 5,84 & 3,63 & 6,98 \\
\hline Lote & PA (\%) & PN fracas $(\%)$ & PN fortes $(\%)$ \\
\hline LA1 & $13,5 \mathrm{a}$ & $13,5 \mathrm{a}$ & $52,0 \mathrm{a}$ \\
LB1 & $25,0 \mathrm{~b}$ & $7,0 \mathrm{a}$ & $34,0 \mathrm{ab}$ \\
LB2 & $28,0 \mathrm{~b}$ & $12,5 \mathrm{a}$ & $26,0 \mathrm{~b}$ \\
Média & 22,16 & 11,0 & 37,33 \\
CV (\%) & 5,84 & 6,28 & 8,52 \\
\hline Lote & Comprimento (cm) & Massa Fresca (g) & Massa Seca (g) \\
\hline LA1 & $8,50 \mathrm{a}$ & $0,655 \mathrm{a}$ & $0,10 \mathrm{a}$ \\
LB1 & $6,34 \mathrm{~b}$ & $0,327 \mathrm{~b}$ & $0,04 \mathrm{~b}$ \\
LB2 & $6,25 \mathrm{~b}$ & $0,258 \mathrm{~b}$ & $0,03 \mathrm{~b}$ \\
Média & 7,03 & 0,413 & 0,05 \\
CV (\%) & 7,87 & 10,51 & 3,52 \\
\hline
\end{tabular}

*Variáveis: germinação aos sete dias (G7). Aos 28 dias: sementes mortas (SM), sementes duras (SD), plântulas anormais (PA), plântulas normais fracas (PN fracas) e plântulas normais fortes (PN fortes). Referente a plântulas normais fortes: comprimento $(\mathrm{cm})$, massa fresca $(\mathrm{g})$ e massa seca $(\mathrm{g})$.

** Médias seguidas pela mesma letra, na coluna, não diferem estatisticamente pelo teste de Tukey ao nível de 5\% de probabilidade de erro. A letra "a" é atribuída ao resultado considerado mais satisfatório na avaliação de qualidade das sementes.

dias para as variáveis sementes mortas, sementes duras e plântulas normais fracas (Tabela 2).

As sementes de LA1 apresentaram a menor média de plântulas anormais (13,5\%), o que é desejável em um lote de sementes, e os lotes LB1 (25\%) e LB2 (28\%) não diferiram entre si e apresentaram médias mais elevadas de plântulas anormais em relação ao LA1. O desempenho de LA1 quanto plântulas normais fortes foi mais elevado em relação aos demais lotes, com $52 \%$ de plântulas que possuíam aspecto normal e expressivo de desenvolvimento.

Cerne, Lavras, v. 20, n. 2, p. 259-266, abr./jun. 2014 
O comprimento, a massa fresca e a massa seca das plântulas normais fortes também foram eficientes para selecionar os lotes, sendo que LA1 apresentou sempre percentuais mais elevados em relação ao outros dois lotes, os quais não diferiram (Tabela 2). Esses resultados diferem do observado em sementes de Pterogyne nitens Tul., em que plântulas normais e anormais não foram consideradas eficientes para estratificar os lotes (NASCIMENTO et al., 2006).

Estabelecimento in vitro: foi possível estabelecer in vitro explantes de $P$. taeda $\mathrm{L}$. na totalidade dos nós cotiledonares obtidos por meio da germinação asséptica de sementes do lote LA1, selecionado por sua qualidade sanitária e fisiológica (Figura 1). Não foram observadas diferenças significativas para as variáveis estabelecimento

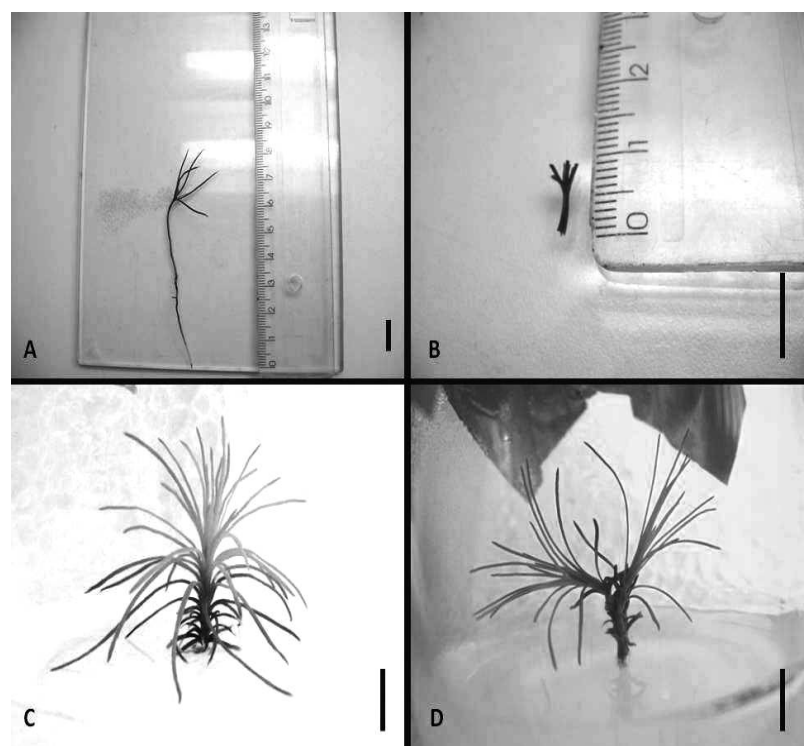

Figura 1 - Aspectos gerais do estabelecimento in vitro de Pinus taeda L. a partir de nós cotiledonares de plântulas oriundas de sementes selecionadas (Lote LA1). Observa-se em: A) aparência da plântula com 40 dias de germinação; B) nó cotiledonar utilizado para inoculação in vitro; C) aparência geral do explante estabelecido; e D) explante com emissão de duas brotações. Barras $=1 \mathrm{~cm}$. Santa Maria, RS, UFSM, 2007.

Figure 1 - General aspects of the in vitro establishment of Pinus taeda L. from cotyledonary nodes of seedlings derived from selected seeds (Lot LA1). It is observed in: A) appearance of seedlings with 40 days of germination; $B$ ) cotyledonary nodes used for inoculation in vitro; $C)$ general appearance of the explant established; and D) explant with the issuance of two shoots. Bar $=1 \mathrm{~cm}$. Santa Maria, RS, UFSM, 2007. e número de brotos quanto aos diferentes meios nutritivos testados. Todos os explantes formaram brotações, as quais apresentaram comprimento médio de $0,52 \mathrm{~cm}$ após 40 dias de cultivo in vitro.

$\mathrm{Na}$ cultura de tecidos, é necessário que o meio nutritivo seja adequado ao desenvolvimento da espécie que se deseja cultivar. Entretanto, observou-se que para o estabelecimento in vitro de P. taeda $\mathrm{L}$. a partir de segmentos cotiledonares os meios testados (MS, $1 / 2$ MS e WPM) não diferiram, o que pode ser considerado um bom resultado, especialmente em termos de economia, pois permite o uso do meio 1/2 MS. Em Cordia trichothoma (Vell.) Arrabida ex Steudel, uma espécie florestal nativa, segmentos apicais caulinares isolados de plântulas apresentaram médias de comprimento significativamente diferentes quando cultivados em meio MS ou WPM, sendo o meio WPM o mais adequado (FICK et al., 2007). Por outro lado, no estabelecimento in vitro de segmentos apicais caulinares obtidos de nós cotiledonares de Peltophorum dubium (Sprengel) Taubert, o meio nutritivo MS foi mais eficiente (BASSAN et al., 2006).

O estabelecimento, a partir de segmentos cotiledonares também evidencia um fator facilitador do cultivo in vitro, dada a facilidade da obtenção de explantes e a manipulação para a micropropagação. Em diversas espécies do gênero Pinus, a propagação in vitro tem sido obtida via embriogênese somática, processo que pode ser considerado mais trabalhoso, já que requer a excisão dos embriões em estágios imaturos. Alonso et al. (2006) obtiveram a micropropagação de Pinus pinea L., utilizando como fonte de explantes cotilédones isolados. Já, para Pinus heldreichii Christ. foi possível obter organogênese a partir de embriões maduros (STOJICIC et al., 1999).

Assim, reitera-se que o processo de estabelecimento a partir de segmentos cotiledonares é possível, constituindo uma forma fácil de obtenção de explantes e também econômica, já que o uso do meio MS reduzido à metade da concentração de sais apresenta resultados satisfatórios.

\section{CONCLUSÕES}

Os gêneros fúngicos observados nos lotes de sementes de Pinus taeda L. foram Aspergillus, Cercospora, Cladosporium, Curvularia, Fusarium, Penicillium, Pestalotia, Rhizoctonia e Trichoderma.

A aferição da qualidade sanitária em sementes de Pinus taeda L. é eficiente na discriminação de lotes, sendo

Cerne, Lavras, v. 20, n. 2, p. 259-266, abr./jun. 2014 
os gêneros fúngicos Fusarium, Penicillium e Trichoderma os de maior sensibilidade para essa finalidade.

A qualidade fisiológica das sementes de Pinus taeda L. possibilita a escolha de lotes com maior vigor para emprego na cultura de tecidos; para tanto, contribuem, em especial, as variáveis de desenvolvimento: plântulas anormais; plântulas normais fortes (plântulas bem desenvolvidas e com características de emissão de radícula e parte aérea superior às demais da unidade experimental); comprimento, massa fresca e massa seca de plântulas normais fortes.

É possível estabelecer in vitro plantas de Pinus taeda L. a partir de nós cotiledonares obtidos da germinação asséptica de sementes de um lote selecionado pela qualidade sanitária e fisiológica superior, sendo que os meios nutritivos MS, 1/2 MS e WPM são igualmente adequados para esse fim.

\section{REFERÊNCIAS}

ALFENAS, A. C.; ZAUZA, E. A. V.; MAFIA, R. G.; ASSIS, T. F. Clonagem e doenças do eucalipto. Viçosa, MG: UFV, 2004. 442 p.

ALONSO, P.; MONCALEÁN, P.; FERNÁNDEZ, B.; RODRÍGUEZ, A.; CENTENO, M. L.; ORDÁS, R. J. An improved micropropagation protocol for stone pine (Pinus pinea L.). Annals of Forest Science, Champaign, v. 63 , n. 8 , p. 879-885, Dec. 2006.

ALVES, E. U.; BRUNO, R. L. A.; OLIVEIRA, A. P.; ALVES, A. U.; PAULA, R. C. Influência do tamanho e da procedência de sementes de Mimosa caesalpiniifolia Benth. sobre a germinação e vigor. Revista Árvore, Viçosa, v. 29, n. 6, p. 877-855, nov./dez. 2005.

BASSAN, J. S.; REINIGER, L. R. S.; ROCHA, B. H. G.; SEVERO, C. R. P.; FLÔRES, A. V. Oxidação fenólica, tipo de explante e meios de cultura no estabelecimento in vitro de canafístula (Peltophorum dubium (Spreng.) Taub.). Ciência Florestal, Santa Maria, v. 16, n. 4, p. 381-390, out./dez. 2006.

BETTIOL, W.; GHINI, R. Controle biológico. In: BERGAMIN-FILHO, A.; KIMATI, H.; AMORIN, L. (Ed.). Manual de fitopatologia. 3. ed. São Paulo: Ceres, 1995. v. 1, p. 365-392.

BITENCOURT, L. F.; HOMECHIN, M. Avaliação da qualidade sanitária de sementes de Guaçatonga
(Casearia sylvestris Swartz - Flacourtiaceae) por três métodos de incubação. Revista Brasileira de Sementes, Brasília, v. 20, n. 1, p. 233-236, 1998.

BRASIL. Ministério da Agricultura, Pecuária e Abastecimento. Regras para análise de sementes. Brasília, 2009. 395 p.

CALDAS, L. S.; PADMAJA, H.; FERREIRA, M. E. Meios nutritivos. In: TORRES, A. C.; CALDAS, L. S.; BUSO, J. A. (Ed.). Cultura de tecidos e transformação genética de plantas. Brasília: EMBRAPA-CNPH, 1998. p. $87-132$.

CARNEIRO, J. S. Testes de sanidade de sementes de essências florestais. In: SOAVE, J.; WETZEL, M. M. V. (Ed.). Patologia de sementes. Campinas: ABRATES/ Cargill, 1987. p. 386-394.

DEBERGH, P. C.; READ, P. E. Micropropagation. In: DEBERGH, P. C.; ZIMMERMAN, R. H. (Ed.). Micropropagation: technology and application. Dordrecht: Kluwer Academic, 1991. p. 1-13.

FICK, T. A. et al. Estabelecimento e crescimento in vitro de plântulas de louro-pardo. Ciência Florestal, Santa Maria, v. 17, n. 4, p. 343-349, out./dez. 2007.

GRIGOLETTI JÚNIOR, A.; AUER, C. G. Doenças da erva-mate: identificação e controle. Colombo: EMBRAPA-CNPF, 1996. 23 p.

LLOYD, G.; MCCOWN, B. Commercially feasible micropropagation of montains laurel, Kalmia latifolia, by use of shoot tip culture. Combinet Proceedings International Plant Propagators Society, Carlisle, v. 30, p. 327-421, 1981.

LORENZI, H. et al. Árvores exóticas no Brasil: madeireiras, ornamentais e aromáticas. Nova Odessa: Instituto Plantarum, 2003. $368 \mathrm{p}$.

MANTOVANI, N. C.; FRANCO, E. T. H. Cultura de tecidos de plantas lenhosas. Santa Maria: UFSM/ CEPEF, 1998.

MARCHIORI, J. N. C. Dendrologia das gimnospermas. Santa Maria: UFSM, 1996. 158 p.

MURASHIGE, T.; SKOOG, F. A revised medium for rapid growth and bio assays with tobacco tissue cultures. Physiologia Plantarum, Copenhagen, v. 15, p. 473-497, 1962. 
NASCIMENTO, W. M. O. et al. Qualidade sanitária e germinação de sementes de Pterogyne nitens Tull. (Leguminosae-Caesalpinioideae). Revista Brasileira de Sementes, Brasília, v. 28, n. 1, p. 149-153, 2006.

PIZZINATTO, M. A. Fusarium spp. em sementes de algodão. In: MENTEN, J. O. M. (Ed.). Patógenos em sementes: detecção, danos e controle químico. Piracicaba: ESALQ/FEALQ, 1991. p. 83-113.

SANTOS, F. E. M.; SOBROSA, R. C.; COSTA, I. F. D.; CORDER, M. P. M. Detecção de fungos patogênicos em sementes de acácia-negra (Acácia mearnsii De Wild). Ciência Florestal, Santa Maria, v. 11, n. 1, p. 13-20, jan./fev. 2001.

SELLE, G. L.; SCHNEIDER, P. R.; FINGER, C. A. G. Classificação de sítio para Pinus taeda L. através da altura dominante, para a região de Cambará do Sul, RS, Brasil. Ciência Florestal, Santa Maria, v. 4, n. 1, p. 7795, jan./fev. 1994.

STOJICIC, D.; BUDIMIR, S.; CULAFIC, L.

Micropropagation of Pinus heldreichii. Plant Cell, Tissue and Organ Culture, Dordrecht, v. 59, n. 1, p. 147$150,1999$.

TORRES, A. C.; BARBOSA, N. V. R.; WILLADINO, L.; GUERRA, M. P.; FERREIRA, C. F.; PAIVA, S. A. $\mathrm{V}$. de. Meio e condições de incubação para cultura de tecidos de plantas: formulações de meios para a cultura de tecidos de plantas. Brasília: EMBRAPA Hortaliças, 2001. 20 p. (Circular Técnica, 24).

UNIVERSIDADE ESTADUAL PAULISTA. ESTAT 2.0: sistema de análise estatística. Jaboticabal, 1994.

XAVIER, A.; OTONI, W. C.; PANCHEL, R. M. Micropropagação e enxertia in vitro de espécies florestais. In: BORÉM, A. (Ed.). Biotecnologia florestal. Viçosa, MG: UFV, 2007. p. 55-74.

Recebido: 20 de dezembro de 2010; aceito: 04 de setembro de 2013. 
